\title{
CT Scanning in Two Cases of Lipoma of the Spinal Cord
}

\author{
R. S. DOSSETOR,* M. KAISER and J. A. VEIGA-PIRES \\ From the Department of Diagnostic Radiology, University Hospital, Utrecht (AZU), The Netherlands
}

Two cases of lipoma of the spinal cord are presented. CT gives a specific diagnosis in this condition without any contrast being given. It is important to make a preoperative diagnosis, as in lipoma of the spinal cord biopsy is dangerous and frequently makes the patient worse. CT is also valuable as the length of the required decompression laminectomy can be assessed.

\section{INTRODUCTION}

CT has been shown to be of value in the diagnosis of some spinal abnormalities (Di Chiro and Schellinger, 1976; Palmers et al., 1976; Nakagawa et al., 1977). In this paper we present two cases of lipoma of the spinal cord on whom CT was performed. We discuss the value of $\mathrm{CT}$ in the diagnosis and asssessment of this condition. The anatomical levels were determined by the method advocated by Dossetor and Veiga-Pires (1978).

\section{CASE REPORTS}

Case 1. A 44-year-old male had a laminectomy 20 years previously when a lipoma of the spinal cord was diagnosed. This was decompressed from C7 to D4. After the operation his neurological deficit was worse; he had some sensory loss below D4 and some weakness in the right leg. Nine years later he started to have bladder dysfunction and since that time he has had a progressive paraparesis. In December 1977 he had pyramidal signs on the right side, with sensory changes mainly on the left side. He walked with difficulty and had moderately severe bladder dysfunction. He was admitted for observation and during this time a CT scan was performed.

It is of interest that in his past medical history there was an unrelated operation for hydronephrosis, four months before the laminectomy. It is also of interest that plain films of the cervical spine were normal and that those of the dorsal spine were also normal apart from the changes due to the laminectomy.

CT was performed both without and with intrathecal metrizamide $(8 \mathrm{ml}$ of $170 \mathrm{mg} / 100 \mathrm{ml}$ solution). CT scans without metrizamide showed the lipomatous tissue clearly (Fig- $1 a, c$ ) and the density levels of the fatty tissue was -90 Hounsfield units (HU). Some areas of normal density (3 HU) increased to $100 \mathrm{HU}$, after the injection of metrizamide (Figs $1 e, f$ ). This showed that the area of normal density was cerebrospinal fluid (CSF) and not spinal cord (Figs. 1a, $c, e, f$ ).

At D4/5 some fatty tissue passed through an intervertebral foramen (Fig. 2a). CT showed that the decompression was incomplete, as the lipoma extended down to D6 (Fig. 3), below the lowest limit of decompression. Below D6 the cord was normal and it could only be identified after the injection of metrizamide.

On this CT examination, at the level of the lipoma, the

*Present address: Royal Sussex County Hospital, Brighton, Sussex, GB. cord could not be clearly distinguished from the lipoma itself.

Case 2. A 29-year-old female presented during pregnancy with weakness in the right leg. She was delivered by Caesarian section, after which her neurological deficit increased. She had some loss of sensation in both legs, and her right leg was weaker than before. She was diagnosed as having cord compression at D10 and had a laminectomy. At laminectomy a lipoma of the spinal cord was found extending up to the cervical region. This was biopsied and a decompression laminectomy was performed from D10 to D1. After the operation her symptoms were worse, and she was unable to walk without help. She also had slight bladder dysfunction. She was referred to our clinic where CT was performed in both the brain and the spinal cord.

Clinical examination at this time revealed a soft tissue mass superficial to the skull in the left parietal region. CT revealed a small bony spur related to it, and confirmed that it was lipomatous tissue. No intra-cranial or intra-orbital lipoma was seen.

CT of the spine showed a fatty mass mixed with the cord from C7 to D10 (Figs. 4a, b). At C6/7 (Figs. 5a, b) the laminectomy was incomplete. The density levels of the fatty tissue were -126 to $-156 \mathrm{HU}$. Plain films of the dorsal spine revealed scallopping of the posterior vertebral bodies (Fig. $6 a$ ) and thinning and separation of the pedicles (Fig. 6b) in the upper dorsal spine. The patient had a further decompression. This confirmed that the upper limit of the tumour was $66 / 7$.

\section{DISCUSSION}

One case of CT demonstration of lipoma of the spinal cord was included in a paper on CT of the spine by Nakagawa et al. (1977). They found, as we have done, that this condition can be diagnosed because the low density fatty masses can be distinguished from CSF, even without the injection of intrathecal metrizamide. Further the density levels are so low that they are characteristic of fat, and thus allow a specific diagnosis to be made preoperatively.

Ammerman et al. (1976) described clinicopathological correlations in nine cases of lipoma of the spinal cord. They state that this tumour is very rare and is less than $1 \%$ of all spinal tumours. It is commoner in women than in men, and usually presents in the second to the fourth decade. They state that it usually involves the dorsal cord alone. 

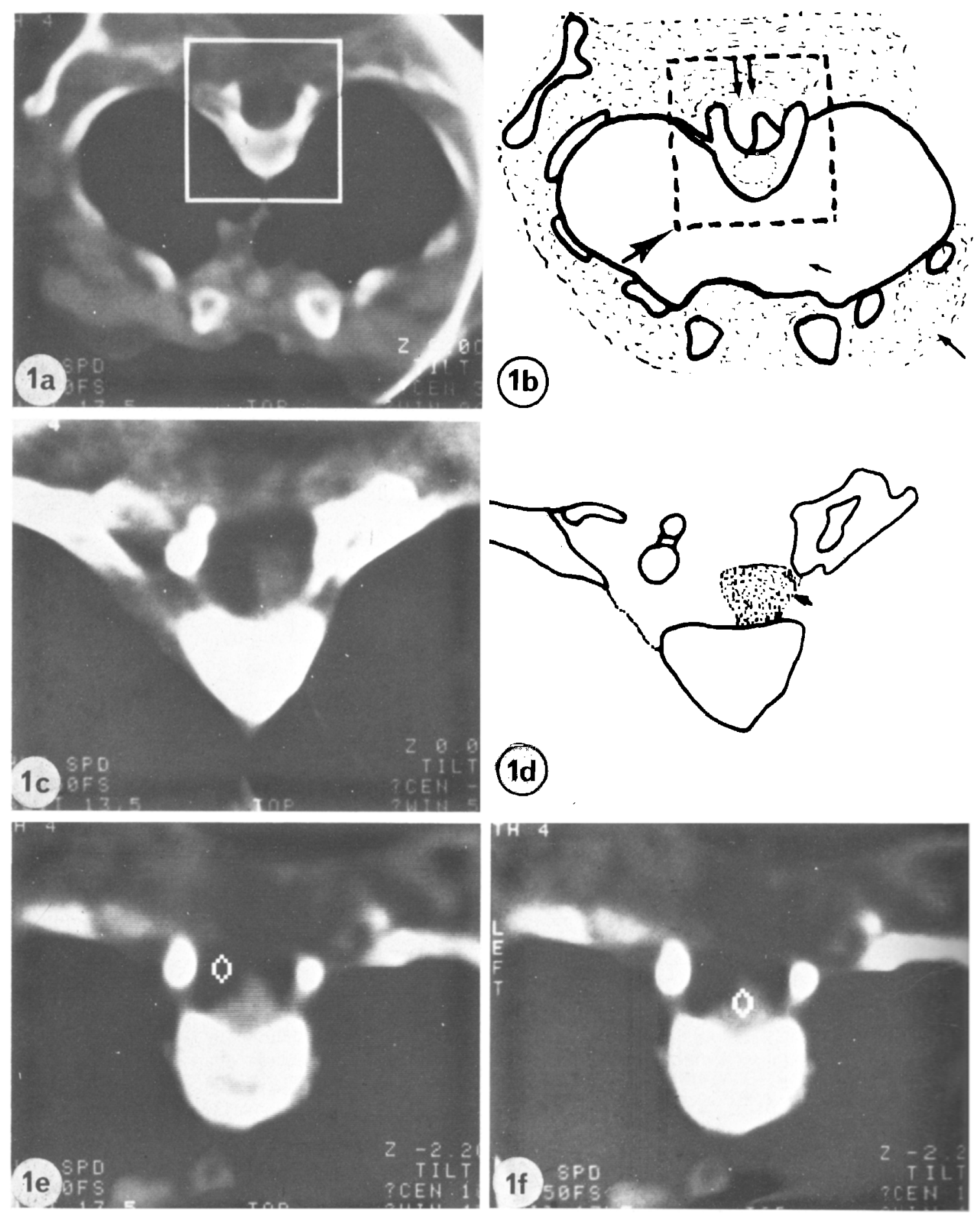

Fig. 1a - Body section at level of mid-D4 showing lipomatous tissue in neurocanal (see detail Fig. $1 b$ ). Note laminectomy (see Fig. 1b).

Fig. $1 b$ - Diagram of Fig. 1a. Latge arrow and square area: detail enlargement Fig. 1c. Double arrows site of laminectomy. Fine arrow soft tissues. Small arrow lung and mediastinum.

Fig. $1 c-$ Magnification detail of Fig. 1a. Normal density ( $3 \mathrm{HU}$ ) represents $\mathrm{CSF}$ and not cord (no contrast) (see Fig. $2 a$ ).

Fig. 1d - Arrow indicating shaded area representing CSF in Fig. 1c.

Fig. $1 e-$ Section at level of upper-D4. Fatty tissue measuring $-99 \mathrm{HU}$ (no contrast).

Fig. $1 f$ - Same section as Fig. 1e. CSF plus metrizamide. Density $100 \mathrm{HU}$ 


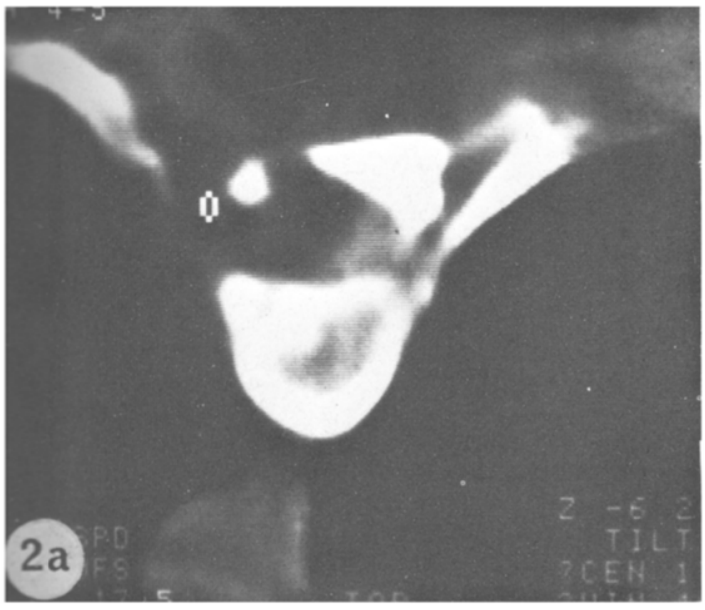

Fig. $2 a$ - Section at level D4/5. Fatty tissue passing through an intervertebral foramen, mean density $-100 \mathrm{HU}$ (see Fig. 2b).
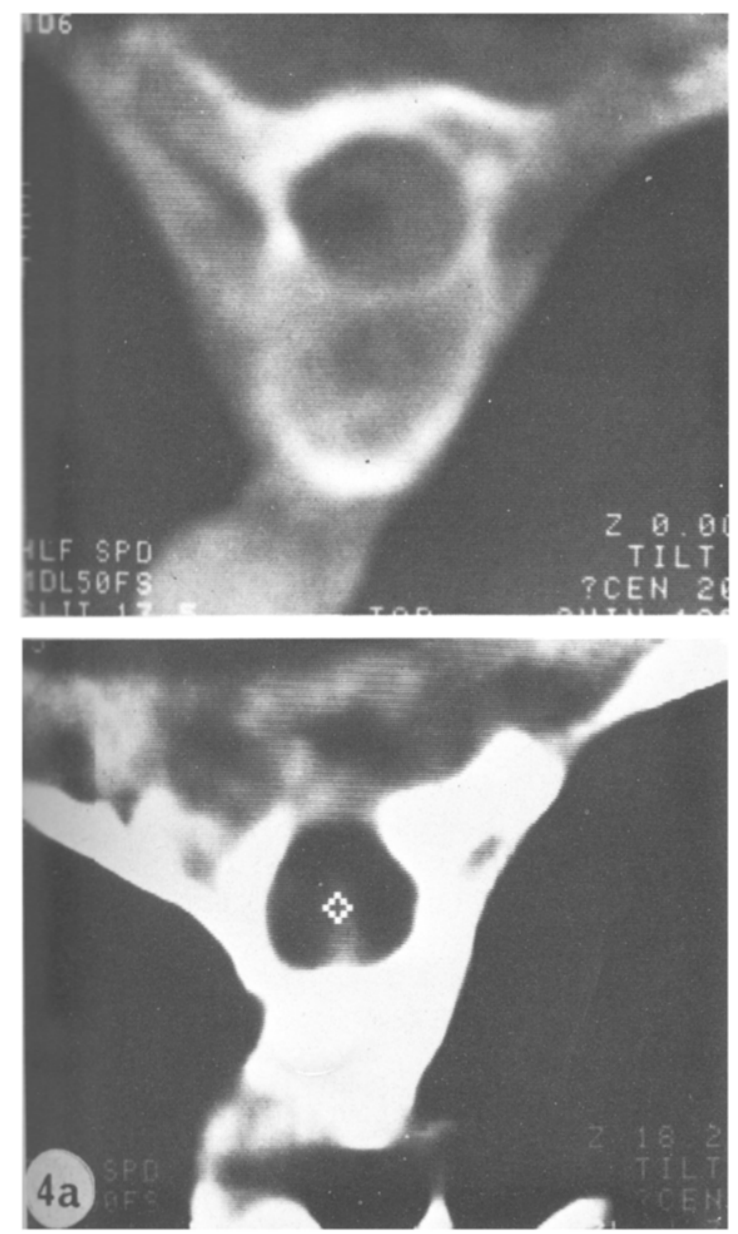

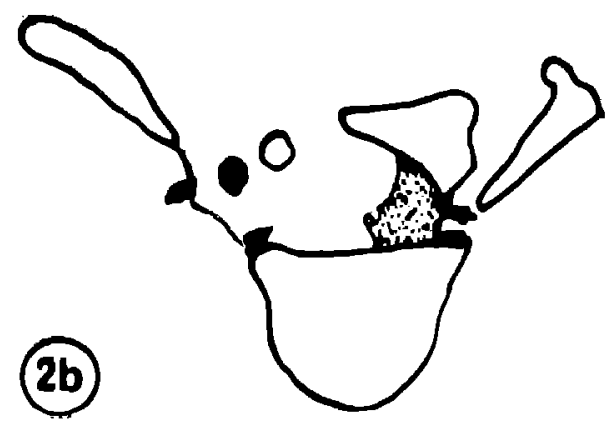

Fig. $2 b$ - Outline of Fig. $2 a$. Double arrow heads point to site of fatty tissue passing through foramen $(-130 \mathrm{HU})$. Single arrow points to CSF plus contrast $(+100 \mathrm{HU})$.

However, in one of our cases, Case 2, the lesion did extend into the cervical cord as far as $\mathrm{C} 5 / 6$. This was shown both at surgery and on CT.

Histologically, these tumours show mature fat with entrapped nerve bundles. These nerve bundles predominate in the periphery of the lesion (Ammerman et al., 1976). This must account for the CT findings where the spinal cord is not distinguishable from the lipomatous tissue. It also explains why biopsy is so dangerous, and why patients can be made worse after operation.

Fig. 3 - Section at level of upper D6 showing fatty tissue in neurocanal. Mean density -53 HU (after contrast). Distribution of fatty tissue and CSF clearly seen. Note presence of posterior arch.

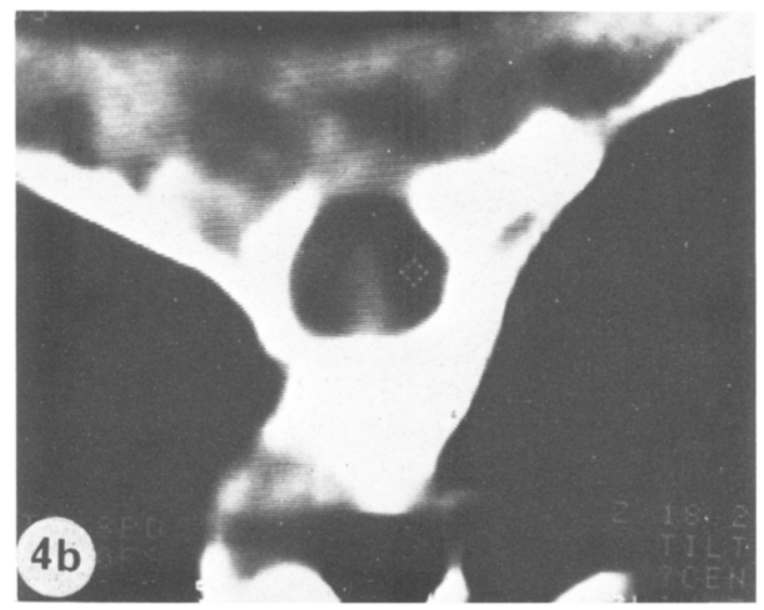

Fig. $4 a, b$ - Section at level of D5. Note laminectomy defect. Fatty tissue mean density values $(b)-130 \mathrm{HU}$. The CSF density measured $3 \mathrm{HU}$ (no contrast). 

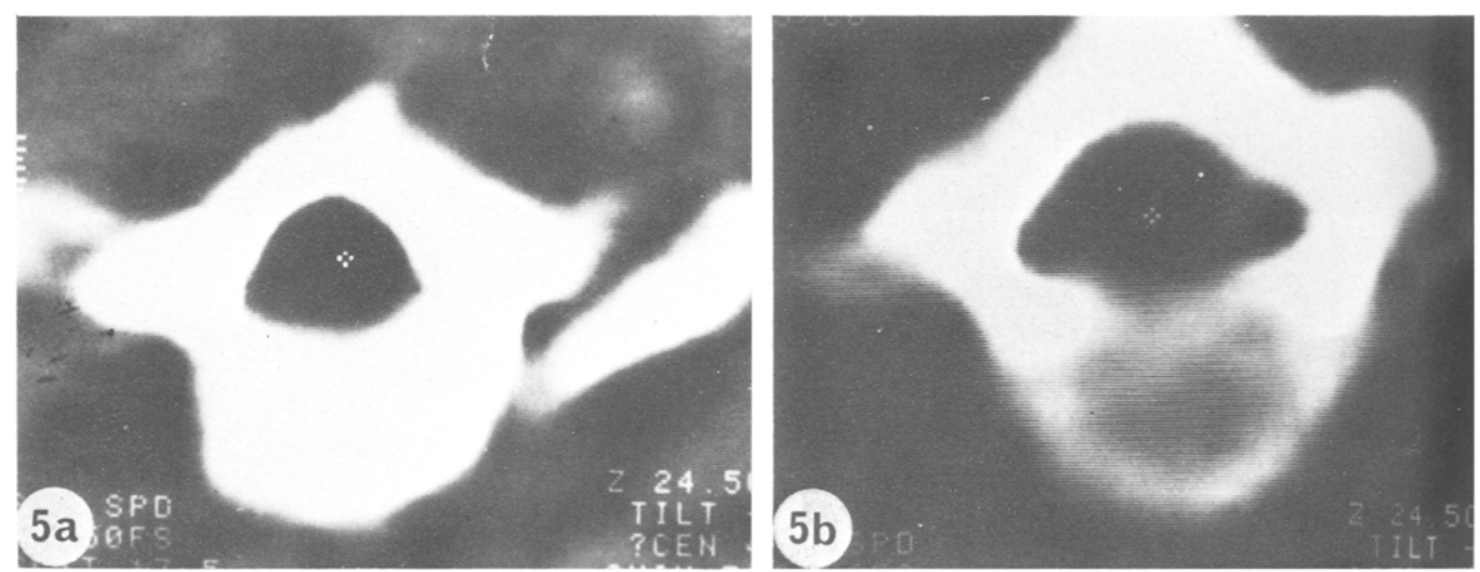

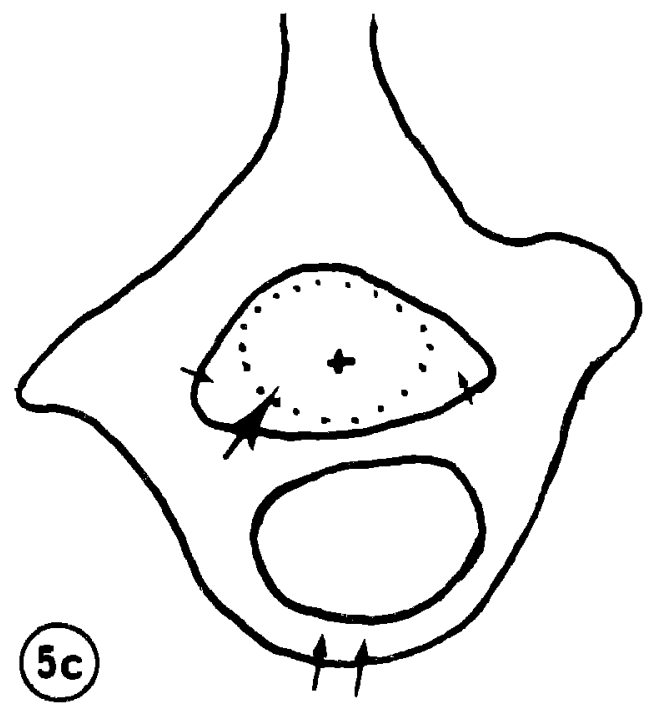

CT can be very valuable in two ways. First, it provides a specific diagnosis, and obviates the need for biopsy. Secondly, as the only effective treatment available (Verbiest, 1978) for this condition is decompression laminectomy, it provides a very good method of assessing the entire extent of the tumour. This enables the operation to be planned more effectively.

The bone changes in Case 2 (scalloping, separation and thinning of the pedicles) have been seen in other cases (Ammerman et al., 1976). They indicate that the tumour was present for a very long time. This supports the view (Ammerman et al., 1976) that these tumours may in fact be congenital hamartomas that only manifest themselves when they have grown to a sufficient size to cause compression of the neural tissue. Evidence for the slow growth of this tumour is also shown in Case 1 where there has been
Fig. $5 a-$ Section at level C6/7 showing presence of fatty tissue. Mean density -138 HU (contrast). Note intact posterior arch.

Fig. $5 b$ - Section at level $\mathrm{C} 5 / 6$ after injection of metrizamide. Normal cord centrally placed (see Fig. 5c). Compare with Fig. $5 a$.

Fig. $5 c$ - Outline of Fig. $5 b$. Large arrow points to surrounding CSF. Double arrows to disc space C5/C6.

a very slow progression over 20 years since the original laminectomy. It is also interesting in this case that not all of the lipoma was decompressed.

Both cases had some unrelated condition before the presence of the lipoma was recognised. Both of them had had surgery a few months prior to the laminectomy, and both were worse after these operations (renal operation, Caesarian section). The significance is unclear, but it is possible that in both cases the anaesthetics affected the lipomatous tissue in some way.

Acknowledgements. - We would like to thank Professor H. Verbiest and Professor A. Kemp for allowing us to use their clinical material. We would also like to thank our radiographers Miss M. Strijbosch and Miss J. Jansen, for their cooperation and Miss V. J. Veiga-Pires and Miss A. van Hell for their help with the preparation of the MMs. Mr G. Eysbroek and Mr H. Breuker of our Department's Photographic Unit prepared the prints for us. 


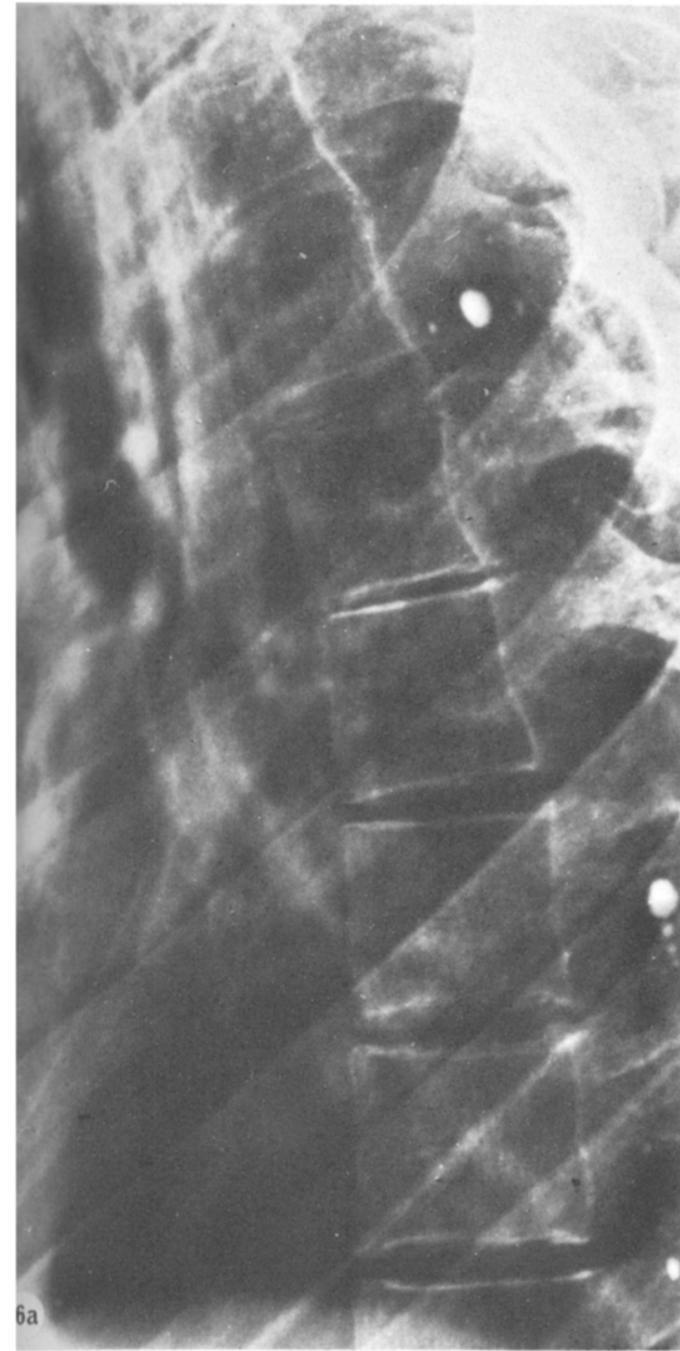

Fig. $6 a-$ Lateral view of upper dorsal spine showing scalloping of posterior vertebral bodies (residual myodil in neurocanal).

\section{REFERENCES}

Ammerman, B. J., Henry, J. M., de Girolami, U. \& Earle, K. M. (1976). Intradural lipomas of the spinal cord. A clinicopathological correlation. Journal of Neurosurgery, 44, 331-336.

Di Chiro, G. \& Schellinger, D. (1976). Computerised tomography of the spinal cord after lumbar intrathecal introduction of metrizamide. Radiology, 120, 101-104.

Dossetor, R. S. \& Veiga-Pires, J. A. (1978). Localization of scanning level in computed tomography of the spine. (In press).

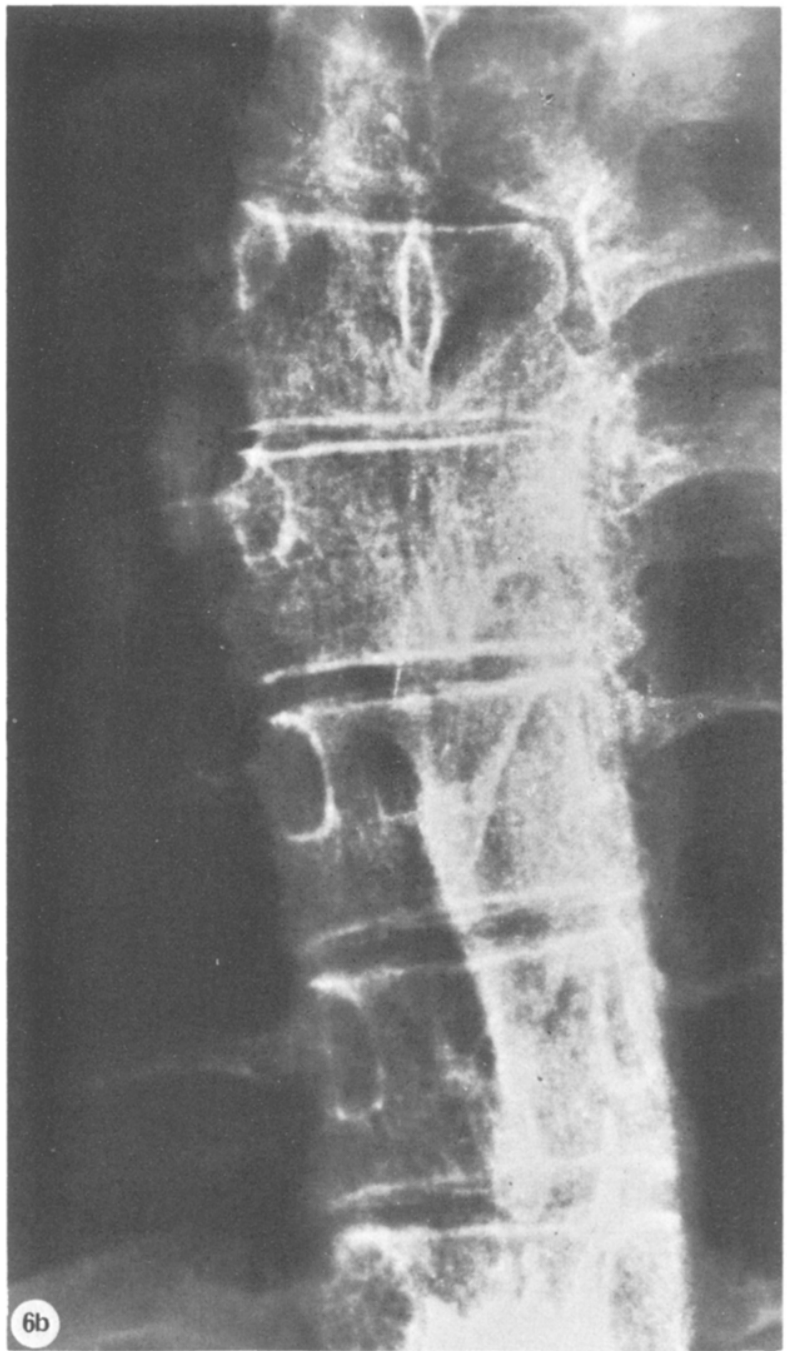

Fig. $6 b-\mathrm{A}-\mathrm{P}$ view of dorsal spine. Note thinning and separation of the pedicles at D5 and D6 (myodil at lower margin of frame).

Nakagawa, H., Huang, Y. P., Malis, L. J. \& Wolf, B. S. (1977) Computed tomography of intraspinal and paraspinal neoplasma. Journal of Computer Assisted Tomography, 1, 377-390.

Palmers, Y., Baert, A. L., Marchal, G. \& Coenen. Y. (1976). Computed tomography in affections of vertebral column and of the spinal cord. Journal Belge de Radiologie, 59, 521-530.

Verbiest, H. (1978). Personal communication. 